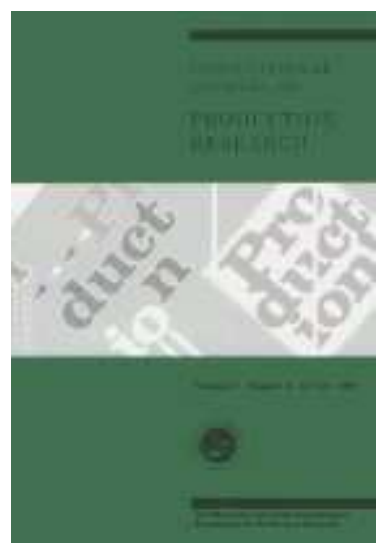

\title{
Path Dependent Constraints on Innovation Programmes in Production and Operations Management
}

\begin{tabular}{|c|c|}
\hline Journal: & International Journal of Production Research \\
\hline Manuscript ID: & TPRS-2010-IJPR-0287 \\
\hline Manuscript Type: & Original Manuscript \\
\hline $\begin{array}{r}\text { Date Submitted by the } \\
\text { Author: }\end{array}$ & 22-Mar-2010 \\
\hline Complete List of Authors: & $\begin{array}{l}\text { Wagner, Helen; Loughborough University, Wolson School of } \\
\text { Mechanical and Manufacturing Engineering } \\
\text { Morton, Susan; Loughborough University, Wolson School of } \\
\text { Mechanical and Manufacturing Engineering } \\
\text { Dainty, A R J; Loughborough University, Civil and Building } \\
\text { Engineering } \\
\text { Burns, N D; Loughborough University, Wolfson School of Mech } \\
\text { and Man Engineering }\end{array}$ \\
\hline Keywords: & INNOVATION MANAGEMENT, CONTINUOUS IMPROVEMENT \\
\hline Keywords (user): & Force Field Analysis, Path Dependency \\
\hline
\end{tabular}

\section{S ScholaroNE" \\ Manuscript Central}




\title{
Path Dependent Constraints on Innovation Programmes in Production and Operations Management
}

\author{
Helen T. Wagner ${ }^{\mathrm{a}^{*}}$, Susan C. Morton ${ }^{\mathrm{a}}$, Andrew R. J. Dainty ${ }^{\mathrm{b}}$, \\ Neil D. Burns ${ }^{\mathrm{a}}$ \\ a. Manufacturing Organisation Group, Wolfson School of Mechanical \& \\ Manufacturing Engineering, Loughborough University, LE11 3TU. UK \\ b. Department of Civil and Building Engineering, Loughborough University, \\ LE11 3TU. UK \\ (Received October 2009; final version received ..........)
}

\begin{abstract}
Innovation has been categorised into levels, ranging from incremental to radical, each of which has the potential to impact on the workforce and the organisation of a company, influenced by contextual factors. This paper investigates the barriers to innovation diffusion in companies working at these two ends of the innovation scale, in order to identify similarities and differences in how levels of innovation affect an organisation and how culture affects success. It also considers these factors in light of the Path Dependency concept. Investigations were conducted on a case study basis, using semistructured interviews. This led to the creation of Force Field Analysis diagrams to portray the findings, which show the radical innovation implementation has experienced greater resistance than the incremental program. Conclusions show that there were many similarities between the radical and incremental innovation projects. Differences were primarily based on project specific forces and those that occur as a result of path dependant forces that have shaped the current working environment. Organisational culture was found to be a significant influence, as all innovation programmes require the involvement of people. Findings of this study will contribute to theory on the differential and similar forces which shape incremental and radical innovations.
\end{abstract}

Keywords: innovation levels; Force Field Analysis; path dependency

\section{Introduction}

Baumol states that "Under capitalism, innovative activity - which in other types of economy is fortuitous and optional - becomes mandatory, a life-and-death matter" (Baumol, 2002). This makes it essential for all organisations (Arias-Aranda et.al., 2001) wishing to survive the capitalist economy that prevails in western society to embrace innovation, especially at this time of global financial uncertainty. Innovation itself can come in several forms, as "an idea, practice or object that is perceived as new by an individual or other unit of adoption" (Rogers, 1995), all of which have the potential to impact on the culture and status quo of an organisation and the individuals within it during Innovation Diffusion. Innovation has been categorised by Henderson and Clark (1990) into four levels, dependent on the effects they have within an organisation: Radical, Architectural, Modular and Incremental (Henderson and Clark, 1990; Afuah and Bahram, 1995), each of which have different effects on an organisation, ranging from the minor incremental to the disruptive radical.

The process of transferring new ideas, known as innovation diffusion, causes a degree of social change, and what may appear to be a simple process is driven by the

\footnotetext{
* Corresponding author. Email: h.t.wagner@lboro.ac.uk
} 
individuals involved and, therefore, gives rise to potential barriers to success (Steele and Murray, 2004) as individuals project their uncertainties over the loss of stability (Topf, 2000) of a situation they have often had a stake in creating (Christensen, 2000). The level of resistance and barriers experienced during this process comes from a variety of reasons, many of which can be linked to company specific decisions, unrelated to the current initiative (Mazzoleni, 1997). For example, the process of innovation diffusion is affected by past events in the history of organisations, which can inhibit the ability of an organization to adopt new ideas, a concept known as 'path dependency' (Liebowitz and Margolis, 1995; Coombs and Hull, 1998; David, 1985).

Having found a lack of business level implementation cases, a finding supported by $\mathrm{Yu}$ and Tao (2009), who noted that "Literature on business-level technology adoption is scarce compared to general literature on examining individual-level technology adoption" and Armbruster et.al (2008) who stated that "the existing literature on organizational innovation is diverse and scattered"; this paper will investigate the barriers to both the uptake and generation of innovation in organisations working at the two ends of the innovation scale; one in radical innovation, the other incremental. Offering information on how the level of innovation affects the barriers created and how culture affects success. It sets out to inform practitioners of the potential issues faced when attempting to propagate a culture more accepting of innovation and the change which this necessitates.

\section{Literature Review}

Morton and Burns (2008) define innovation as threefold: "the process of bringing new and improved products and processes to market; developing, adopting and adapting manufacturing processes to enhance productivity and product quality; and developing, adopting and adapting business practices to enhance the performance of the firm." All of these have the same goal: to improve efficiency and ensure the organisation remains competitive in its market. In this study, it is the organisation's innovativeness that is important, considering the propensity a firm has to adopt innovations (Garcia and Calantone; 2002, Damanpour, 1991; Rogers, 1995), both in terms of new technology and process improvements.

Recent publications on innovation diffusion into organisations have focused on topics from training (Sharma \& Yetton, 2007), patterns of adoption (Freitas, 2008; Xue et.al, 2008) and effects of firm size (Freitas, 2008; Battisti and Iona, 2009), to monitoring and measuring diffusion (Armbruster et.al 2008) and recognising its differing stages (Freitas, 2008; Yu and Tao, 2009; Carayannis and Turner 2006; Larsen, 2005; Lapointe and Rivard, 2005). However, the majority have explored the effects of management involvement in the process (Panuwatwanich et.al, 2009; Peansupap and Walker, 2006; Lapointe and Rivard, 2005; Dong, 2008; Lyytinen and Rose, 2003).

In their study, Sharma \& Yetton (2007), established that although training is generally seen as an essential component in the innovation diffusion process, it is really only critical where technical complexity and task interdependence are high; which has the potential to impact on many planning innovation adoption. Freitas, (2008) and Battisti and Iona, (2009), found that firm size had an impact on innovation diffusion; showing that larger firms were more likely to adopt organisational innovations (Freitas, 2008) and use them more intensively, than small, independent firms (Xue et.al, 2008). Armbruster et.al (2008) categorised innovations into structural - those which change responsibilities, information flow, hierarchical levels 
and divisional functions - and procedural - those that affect routines, processes and implement new procedures. This allows for a structure in a monitoring system that is clear what it is measuring, which is further broken down to identify four areas for consideration: i.e. complexity, lifecycle and quality of innovation, along with extent of use.

There are many different stages in the diffusion process, that begin before the decision to adopt, at which point information begins to become available and opinions begin to be shaped ( $\mathrm{Yu}$ and Tao, 2009); views which change as the stages progress (Larsen, 2005). Observations made by Carayannis and Turner (2006) showed that many of the most successful firms have undertaken what have often been lengthy and expensive pilot studies as the first stage in their diffusion process. The work of Lapointe and Rivard (2005), explored resistance behaviour through diffusion stages; identifying behaviour that escalated from passive individual to actively resistance coalition groups. This has led them, Lapointe and Rivard (2005), and others (Yu and Tao, 2009;) to advise that, at least in the initial stages, that resistance should be looked at on an individual level and their interactions (Wagner et.al) rather than considering the group as a 'unified entity' and management responses modified accordingly. The general consensus amongst authors (Panuwatwanich et.al, 2009; Peansupap and Walker, 2006; Lapointe and Rivard, 2005; Dong, 2008; Lyytinen and Rose, 2003), is that top level management visibility is critical to the success of an innovation initiative. Peansupap and Walker (2006) noted how this should manifest at the different stages of diffusion; demonstrating commitment in the early adoptive phase by making resources available, followed by encouraging users through adaptation and rountinisation of the innovation into normal working practices and supporting with the appropriate technology and training to develop the necessary skills. Dong (2008) conformed to this view, adding that senior management should be visibly supportive throughout the stages of diffusion and should not assume that staff will be aware of their support, by paying attention to change management and satisfaction of users. This will also include (Lyytinen and Rose, 2003) that management recognise the demands and implications involved the change. Inspiring creativity and challenging staff to promote the development of new ideas was also considered a role of a leader in the diffusion process; a strategy that should lead to a greater propensity for supporting and facilitating the innovation initiative (Panuwatwanich et.al, 2009).

Innovation typology is a widely discussed topic, with many different scales being offered by authors (Garcia and Calantone, 2002). Henderson and Clark's (1990) four level typology, developed from Abernathy and Clark (1985), was considered to be the appropriate structure in the analysis of the two case studies, which fall at either end of the scale, when related to organisation based innovation. It is considered that the culture for radical innovation differs greatly from that of incremental innovation (Greenwood and Hinings, 1993), and must be considered by managers undertaking innovation projects (Garcia and Calantone, 2002; Oke, 2007). Management style also differs and a thorough understanding of the process must exist in order to make sense of complex and uncertain conditions (Tidd, 2006). With success resting on management creating sufficient level of enabling influence to support the process (Sharma \& Yetton, 2003), they must obtain feedback from staff and modify their supportive actions correspondingly (Dong, 2008).

Radical innovation, as seen in Case 1 , is disruptive in nature, rendering current equipment and the connected competencies obsolete (Garcia and Calantone, 2002). It is defined as "change that sweeps away much of a firm's existing investment in technical skills and knowledge, designs, production technique, plant and equipment" 
(Utterback, 1996) and is characterised by a greater level of risk (Garcia and Calantone, 2002). Although innovation is often associated with radical change (Oke, 2007), it was suggested by Morton and Burns (2008) that most successful innovations come from a programme of incremental changes, emanating from efforts of individuals in many areas not confined to research and development. Incremental innovation is based on "doing what we do, but better" (Tidd, 2006), refining existing technology and processes, leading to standardisation and a position of status quo in an improved organisation (Garcia and Calantone, 2002).

Within any organisational undertaking, there are potential barriers and enablers that come from both the program being pursued and the individuals involved in the process, which is potentially different in every organisation as "innovation is a process which is intrinsically firm specific" (Coombs and Hull, 1998). Context has been shown to be an important factor in the understanding of innovation and its challenges, as set out by Afuah and Bahram (1995), as the 'hypercube of innovation'. This argues that what is seen as incremental in one context may cause radical consequences in another (Harty, 2008). Issues surrounding fit with the organisational structure and top management level support exist, along with work patterns and availability of resources (Morton and Burns, 2008). Many of these issues can be resolved by the formulation of an innovation strategy (Babbar and Rai, 1990), which should then be communicated throughout the organisation to elicit buy-in (Oke, 2007). This has been shown to be important in the field of radical, technology innovation implementations, where more failures result from organisational issues than technical ones (Voss, 1986; Babbar and Rai. 1990; Machuca et.al, 2004).

Human factors play a part in achieving success; barriers to which have been identified at all levels from the individual, and the team, to the organisation as a whole (King, 1990; Kratzer et al., 2005). Organisational culture may have an affect on potential for success. Hill and Jones (2004) explain culture as "the specific collection of values and norms that are shared by people and groups in an organisation and that control the way they interact with each other and with stakeholders outside the organization". In mature organisations these can be deeply embedded and, although they initially brought about success, they can inhibit the capability to embrace new ideas (Dougherty and Cohen, 1995; Leifer et al., 2000). Working within rigid structures potentially has a negative effect on innovation (Amabile et al., 1996), and a lean organisation may not allow for much 'idea time' (Anderson and West, 1998). However, innovation can be nurtured by a more caring atmosphere (Kratzer et al., 2005; Zarraga and Bonache, 2005). Initiatives to manage resistance and promote involvement may include a human resource policy (Oke, 2007) and the designation of innovation champions (Rogers, 1995), especially in cases of radical innovation (Garcia and Calantone, 2002). A further, important issue in motivating individuals to engage with the innovation programme is that of the perception of trust, both in management and in their colleagues, the establishment of which will allow the sharing of knowledge and ideas (Morton and Burns, 2008).

As each organisation faces the challenges of new technology, the process they go through is different every time. One potential explanation for this difference is known as Path Dependency (PD). One term that is often associated with PD is 'history matters'. Simplistically, this explains that the decisions made, or acts of 'fate' that happen at the beginning of a venture have consequences further down the road, which may not be anticipated, and can constrain future activities (Greener, 2005). If the notion of history means that "What we have today is in part a consequence of what we had and what we did yesterday" (Liebowitz and Margolis, 1995), it also brings to 
any new venture the associated 'inherited' culture and technological skills. In many cases it can be the things that the organisation had little control over that have had an impact, such as external events; these cannot be underestimated in their influence over the process, as it is considered to be dynamic and takes on characteristics of its history (David, 1985), and can remain affected by these events long term (Liebowitz and Margolis, 1990). The concept of path dependency has been related to many areas of study in addition to technical innovation (Patel and Pavitt, 1997; Dobusch, 2007); including economics (Coombs and Hull, 1998; Boas, 2008), finance (Deeg, 2001), social sciences (Greener, 2005), and biology (David, 2001). In searching for a definition of PD, authors have made several observations of the concept; that it is dynamic (Liebowitz and Margolis, 1990), non-reversible and evolutionary (David, 2001).

When considering work published on innovation and PD, Coombs and Hull identified three domains in which PD is observed within an organisation, these being 'technology-as-hardware', 'knowledge base' or 'shared mental framework of fundamental design concepts' which can be seen to be connected to the technologies employed, and the 'routines' that exist to allow workers to perform effectively (Coombs and Hull, 1998). Whilst it is true that often small events are averaged out by history (Schwarz, 2004) this does not always happen (David, 2001), resulting in PD where small, seeming inconsequential or random events at a critical juncture can play a part; in some cases creating disproportionately large and long-lived consequences further down the path (Liebowitz and Margolis, 1995; Deeg, 2001; Schwarz, 2004). Arthur offers examples of these types of events as "unexpected orders, chance meetings with buyers, managerial whims" (Arthur, 1989).

The term 'lock-in' (Greener, 2005; Liebowitz and Margolis, 1995; Deeg, 2001; David, 2001; Arthur, 1989) is often used to describe the process of moving into the reproduction phase of the path (David, 2001), after change has taken place. Within this process the organisation must find ways of sustaining the equilibrium in order to 'lock out' competing ideas (Greener, 2005); these mechanisms are central in the concept of PD (Deeg, 2001). This locked-in state can be a positive or negative situation, as firms can also become locked-in to a situation, which is no longer the most efficient solution for them, by factors such as financing, when it is still more cost effective to continue to use inferior equipment than invest in new (Liebowitz and Margolis, 1995).

This paper aims to bring together many areas of innovation research, comparing the barriers to innovation diffusion in companies working on radical and incremental programs, in order to identify where similarities and differences occur and how levels of innovation affect an organisation. It also considers how culture affects success in innovation programs and contemplates these factors in light of the Path Dependency construct.

\section{Methodology}

For this work to address the issues identified, the case study methodology was chosen. In an era where Open Innovation (Perkmann and Walsh, 2007; Morton and Burns, 2008) is encouraged, conducting case studies in collaboration with organisations was the most appropriate research methodology. This approach allowed for the use of multiple data collection methods that created the richest picture possible. It also provides a useful example to others of practical research findings from organisations attempting change over an extended time, something that $\mathrm{Yu}$ and Tao (2009) and Armbruster et.al (2008) also found lacking in extant literature; and which forms an 
important part of explaining the nature of resistant attitudes and behaviours (Lapointe and Rivard, 2005) and are especially interesting and under reported (Perkmann and Walsh, 2007)

Case studies are used to study complex social phenomena (Yin, 2003) and are a useful tool in studying behaviour in organisations and new or emerging behaviours. They involve research of a real situation (Ritchie and Lewis, 2006), with the behaviour viewed in the context of all the interactions going on around it rather than in isolation (Cassell and Symon, 2004; Rowley, 2002). Qualitative cases seek to find the underlying factors, coming from perceptions and feelings of people as they undergo experiences related to the process, uncovering what lays beneath the objective evidence (Gillham, 2005). Their ability to achieve this comes from the richness of data collected using the various sources of evidence (Rowley, 2002), which can be used to provide description, and generate new, or test existing theory (Eisenhardt, 1989). Based around a set of research questions or hypotheses, a case study is conducted over time (Cassell and Symon, 2004), using varied methods of data collection (Yin, 1981), such as interviews, focus groups and observations, in order to create as full a picture of the situation as possible (Ritchie and Lewis, 2006). This may be enhanced by the use of quantitative methods (Bryman, 1989) in some cases.

The cases introduced in this paper were investigated as part of two larger research projects, but were brought together to show the differences and similarities experienced by organisations innovating in different ways and at different levels. Case 1: a large automotive manufacturer that has implemented highly innovative and complex technology and is encouraging staff to embrace it and be innovative in how it can be utilised. Case 2: a large automotive supplier that has undertaken a lengthy program of improvement, and wishes to promote innovative thinking and the acceptance of innovative improvements, put forward by the workforce. During the investigations, semi-structured interviews were conducted giving rise to substantial sources of qualitative data. This data was then coded into themes for further analysis.

Barriers and enablers to the innovation identified within the process at each of the case organisations were represented in visual form using the Force Field Analysis method. Force Field Analysis is a technique that was developed by Kurt Lewin in the 1940's (Dezieck, 2003; Dhillon, 2006) and was published in 1951 in the work Field Theory in Social Science (Lewin, 1951). It is a 'time honoured' qualitative analysis tool (Schwering, 2003), included in many organisational behaviour (Thomas, 1985) and strategic management texts (Elliott et.al., 2001). Primarily utilised to inform the strategy when an organisation wishes to undertake change (Mersha, 1997; Thomas, 1985), it is used to identify and evaluate the forces at work (Thakkar et.al., 2006; Schwering, 2003); where a force refers to any factor that has the potential to impact on an organisation, capable of changing its state (Schwering, 2003). Working on the premise that an organisation is in a state of balance (Londeix, 1995) or, as illustrated in, "quasi-stationary equilibrium between driving (promoting) forces and restraining (hindering) forces" (Oliver and Harrison, 1996), the technique is used to assess how great an affect the forces will have on the change process. The forces that resist change attempt to maintain the status quo (Salaheldin, 2003; Thomas, 1985), but change cannot be enacted without creating this temporary imbalance in the equilibrium (Mersha, 1997).

Strengths of this technique are its ability to create an overall picture of the situation, identifying assets as well as inhibitors (Thakkar et.al., 2006); it clearly identifies all variables, which allows for an objective evaluation of all aspects of the 
planned process (Thomas, 1985). Such an approach offers the potential to 'unearth fresh options' (Jones and Sims, 1993) and not only provides a list of forces for and against, but also can identify individuals and groups that will affect, or be affected by the change, including those not part of the subsystem directly related to the change (Thomas, 1985). Using this technique allows the perception of forces to be quantified in a formalised way, which gives rigour to the decision making process making it transparent and explainable (Swinton, 2007). There are though, identified criticisms of the technique, based primarily on its ability to withstand bias. It can be affected by the experience, personality and style of the analyst (Schwering, 2003). However, this individual bias can be mitigated by performing the technique in a group (Thomas, 1985), often in a brainstorming activity (Jones and Sims, 1993).

The process is carried out in a series of steps which begin with identifying the current position of the organisation and the required position after a change would take place (Dezieck, 2003); this information is then used to analyse the forces at play.

Step 1: identify the driving and restraining forces that may affect the change, taking care to look at all aspects including "intangible or emotional factors" (Oliver and Harrison, 1996).

Step 2: score each force based on its level of effect, using a rating scale, for example: 1 (weak) to 5 (strong), taking account of their limitations and constraints (Thakkar et.al., 2006). Create a Force Field diagram to depict the forces (Schwering, 2003) on either side of a central divide (Dhillon, 2006), assigning representatively sized arrows to driving and restraining in opposing directions (Londeix, 1995; Oliver and Harrison, 1996; Swinton, 2007; Mersha, 1997; Thomas, 1985).

Step 3: total the forces driving and restraining the change to assess the potential success of the planned implementation.

This gives a picture of the current balance and offers the potential to drive the process forward by addressing and prioritising the forces working for and against the change. Where the restraining forces outweigh the drivers making change difficult, the forces should be examined to find ways to lessen their effect.

During this study factors that influenced the innovation programmes at the case study organisations became clear, from the observations and interviews carried out. Analysis was carried out in brainstorming sessions of involved researchers and results were assessed using the Force Field Analysis technique to gauge the current situation and the potential for success of the enterprise. Scored arrows were allocated based on the frequency issues were raised and the importance that the respondents placed on that factor.

\section{Results}

Case 1 explored an organisation implementing a new advanced manufacturing technology (AMT); known as Rapid manufacturing (RM). An undertaking such as this has been shown in the past to create significant disruption within an organisation and on its individual workers, meaning they must be on-board with the decision to innovate the production process. The implementation had been under way for some time at the point of study but with limited success, making progress slow. Results are shown in Figure 1. 


\section{[insert Figure 1 about here]}

As the diagram shows, the barriers significantly outweigh the enablers, going some way to explain the lack of progress. It also illustrates just how much of the innovation depends on the attitudes of the individuals involved. In this case, however, the immaturity of the technology must also be seen as a major obstacle to exploitation.

For the organisation in Case 2, the innovation being considered was based on incremental improvements to the working practices, processes and production facilities; having previously undergone a lengthy period of business improvement to achieve Lean working conditions. In order to be successful, the program relied on the ideas of staff working in the areas of improvement, requiring them to be creative and challenge accepted practices. The results of Case 2 are shown in Figure 2.

\section{[insert Figure 2 about here]}

It can be deduced from Figure 2, that the innovation initiative has shown a degree of success, with the support for the process outweighing the resistance. However, in order to optimise the full potential there are still many areas for the organisation to address.

\section{Barriers and enablers}

Assessing the forces that exist within the two innovation initiatives, it can be seen that there are three types of forces: those that could be generally associated with innovation programmes; ones that are innovation specific; and others that relate directly to the individual organisation and are therefore path dependant.

Comparing the generic forces, it can be seen that there are some that make a significant impact on the success of the venture. It is important that the programme of innovation fits with the existing direction and objectives of the organisation. This can be seen as less aligned in Case 1 than in Case 2, as in recent years the majority of production has been outsourced, thereby building a network of external suppliers rather than increasing capabilities in-house, as would be the expected situation with radical technology implementation. Case 2 has undertaken major reorganisation in order to create a Lean working environment and as such a programme of incremental innovation fits perfectly as an ongoing direction. Strategy is an important factor and for Case 1 the innovation implementation was not planned in advance as an innovation programme. Rather, it was allowed to evolve; resulting in a lack of direction and slow, sporadic progress.

In direct contrast, the programme at Case 2 was carefully considered and planned and has shown a far greater level of success to date. This is also connected to the level of top management support shown, with Case 2 management being firmly committed to a predetermined effort rather than the unstructured, somewhat experimental approach of Case 1. In addition to this support, the nomination of change champions has had an impact on both programmes, a step more usually associated with radical innovation. Proving a significant ally in Case 1, the effects of the change champion may have actually been more fruitful in Case 2, as the individuals not only serve to influence others but in an incremental innovation programme, can begin to make initial changes that can show real results. 
Organisational philosophy plays a big part in the innovation process, especially in long established firms with deeply embedded routines. It also affects individuals who become invested in the status quo and, if not sufficiently convinced of its merits, can see potential innovation as change for change's sake. This is the situation at both of the organisations. At Case 1, where not all individuals can see the point of replacing equipment and processes that work perfectly well in their eyes with a new, unknown system. At Case 2 a similar, if less pronounced situation exists. Having gone through a widespread Lean Manufacturing initiative, some think the processes have already been improved and do not set out to innovate further. In both cases, this situation also links to a phenomenon that can be experienced in any type of change, especially in long established firms with little staff turnover; the legacy of initiatives past.

Both the radical and incremental programmes have come after many past innovations - some successful, some not - which causes individuals to view any new initiative with scepticism. It taints their perception and puts up barriers that have no relation to the current programme and are therefore, difficult to address. In order to counteract this, widespread acceptance of the initiative being pursued is needed. Efforts to create this level of acceptance at Case 1 have included internal 'road-show' events where key members of staff have gained access to information provided by experts in the field. Case 2 has harnessed Visual Management techniques to highlight successes in order to win-over those who are negative or disinterested. It must be recognised that, from both a technical and human resource perspective, that any new innovation initiative will take time to develop and this time must be allocated by management before measures of success are taken.

One issue that affects both the radical and incremental change is the observed changes to the job roles and the level of tasks within them. The forces termed 'blurring of job roles' and 'lack of empowerment' are connected, as one leads to the other. Perhaps by not anticipating the changes to job roles, those in authority have not allowed employees in lower level positions to become empowered to take the lead and, in some ways, to take on tasks from those above. These higher level individuals also feel the change and resist the loss of what they perceive as part of their role, which was previously above those now taking on the tasks.

For radical technology innovation there are several forces that come directly from the nature of the innovation, its potential benefits and the knowledge needed to optimise it. Advantages that come from the technology, helping to drive it forward, include the flexibility of the technology that allows for many different parts to be processed simultaneously without tooling, and leads to the potential for customisation of goods. In-house manufacturing allows for a much shortened supply chain and removes issues of confidentiality that may exist when utilising external suppliers. RM is currently immature when compared to established processing techniques and this brings with it many problems. Not only does it lead to unrepeatability and therefore unreliability, but to resolve these issues requires a level of knowledge that does not currently exist within the organisation and industry as a whole, thus holding back the technology and not just on an individual organisational basis.

The incremental innovation programme at Case 2 has brought about forces that come from the organisation itself, its culture and approach. As a well established firm with low staff turnover and high years of service, staff have become invested in the organisation and care that it is working at its best, both for their pride in the organisation and job security. There is a tremendous feeling of loyalty which is amplified by the work the union representatives do with management to ensure success and a good working environment. One element of the strategy that is proving 
successful is the provision in the working week for idea generation, an idea not common in Lean organisations, with a designated meeting time every week. This shows staff just how important management see the initiative and gives them a forum to put forward their innovations in a supported way. However, in the past, poor communication of the response of management to innovative suggestions has led to individuals becoming disillusioned and, where credit has not been correctly attributed, some have felt aggrieved. The issue of reward has also been discussed, with some feeling the current system inadequate or inappropriate when related to effort; this must be addressed.

\section{Radical $v$ incremental innovation}

It can be seen that many of the same forces exist in both the radical and incremental innovation programmes. Potential explanation for this relates to the size of the organisation and the ambition of the programme. As both are large and the programmes affect many staff in areas not always directly related to manufacturing, the effects of the initiative are widespread and amplified by the number of staff involved. This is not unexpected with radical innovation as it is anticipated that this will cause technology, knowledge and job roles to change. However, it is less obvious that these effects would be as widespread with incremental change. In light of the similarities experienced, it is thought that a similar management approach would be needed, contrary to suggestions in the literature. Although it can be seen that the management at Case 2 have approached the innovation with much more understanding of what will be required and what can be achieved than Case 1, who appear to have underestimated the extent to which a radical innovation can affect their organisation. In these cases it could be considered that Case 1, as a radical change in a fairly limited context, was a deep change that concentrated a narrow focus on the business, whereas Case 2, was seeking incremental change in a way that affected the whole business and so was a shallow change that had a wide effect on all of the plant, perhaps explaining why many similarities were found.

It has been said that incremental innovations tend to show more successes than radical; which at a similar stage in the two programmes has been shown to be the case. This may, however, be due to the nature of incremental innovation being broken down into stages, each of which in itself can be a success. Whereas, in order for radical innovation to achieve success, all of its elements must come together, meaning that reaching a specific stage in development does not ensure that the overall initiative will not eventually fail.

\section{Organisational culture}

Extant theory has shown that organisational culture affects the potential for innovation in organisations (Amabile et al., 1996) and that has been seen to be the situation in these cases. Case 1 is a highly bureaucratic structure where staff know their roles and the tasks involved within them, leading to a situation where challenging the status quo has great affect on the individual, leading to resistance. The routines and work practices that are embedded are firmly set and hard to change, especially without the necessary support and influence of committed management. Case 2 has been seen to be a procedural organisation, but one that is open to change, especially having undergone a fundamental program to achieve Lean status. The overall environment is populated by staff who value their job and the role they have in 
keeping the organisation successful; they see improving things as part of the norm. Supportive management with a positive industrial relations climate creates an atmosphere that fosters innovation and aims to make every individual feel involved and valued. Although both organisations have seen a level of success, which in part is limited by the type of innovation, it is felt that the differences in organisational culture and attitudes play a significant part.

\section{Path Dependency}

Coombs and Hull (1998) believe that the process of implementing an innovation is firm specific and as such path dependant. This has been shown to the case in each of the case companies of this study, as the trajectory has been different based on the initial conditions found within the organisations.

Path dependency, in its most traditional form, relies on the assumption that small, somewhat insignificant events lead to the large consequences, which shape the direction of an organisation (Schwartz, 2004). Others, such as Deeg (2001) and Liebowitz and Margolis (1995), accept that larger events and purposeful decisions also cause path dependent results and constrain future choices (Teece, et.al, 1997), which is a major constraint on companies' dynamic capabilities. For the case companies this is more likely the situation as, rather than the result of chance, many of the current conditions have come from decisions taken in the past. Case 1 is a long established company that has made its reputation on providing not only luxury but personalisation of their products. The technology is used primarily to tap into the market for customisation and the decision to focus on this marketing strategy makes it an appropriate technology. Other past decisions, such as the choice to outsource the majority of components and establish a tiered supplier network, have set a situation that makes RM implementation more difficult than in other organisations. At Case 2, the culture of long service means that many have been at the organisation through previous failed change initiatives that have affected their perceptions of any potential venture, causing some to be sceptical and detach from the programme.

One area that has proven to be path dependent at the companies is that of routines; the importance of these routines and the role they play in an organisation was noted by Coombs and Hull (1998). These established routines go on to inhibit change as they become ingrained and become the norm after what potentially could be years of optimisation to the current situation (Andreua and Ciborrab, 1996). This has been shown to be true at the case organisations, especially Case 1, a highly procedural company, which in itself inhibits change and where even the most basic of updates must go through a formal process that takes weeks and so deters engineers from making changes in all but necessary situations. Engineers and designers have become accustomed to using techniques and materials that they know will work in a certain situation, rather than expanding their options to include new possibilities that may, in fact, meet their needs better. Routines of this kind actually form a barrier to the potential benefits of the innovations being implemented. Case 2, although procedural, has learned through previous initiatives to adapt to change and challenge procedures and set-ups that are not optimal, supported by a union established long ago; these past decisions and events actually aid in the innovation process. However, the formalised structure established at both organisations inhibits change, as staff see their roles as clearly defined and the changes begin to blur those roles, often without sufficient empowerment for them to embrace the added levels of responsibility. 
The process of radical innovation at Case 1, when compared to the conditions set out in the theory is undoubtedly path dependant, with many factors that are company specific working against the acceptance of the technology. Case 2 is less pronounced, but still subject to path dependant issues in many parts of the incremental innovation process.

\section{Conclusions}

This paper provides a contribution to extant literature on the barriers and enablers of innovation at different levels, highlighting the similarities and differences that exist and the effects of company size. It shows that initial perceptions of the terms radical and incremental may not be sufficient to determine the level and types of resistance that may be encountered.

Supporting the work of Coombs and Hull (1998), findings show that much of the implementations have been firm specific; however, there were also generic barriers found that could affect any implementation. The barriers identified within the two case study organisations can be split into; 1) those common to both and therefore may have the potential to affect many organisations; 2) innovation specific forces, that occur as a direct result of the innovation being undertaken, especially prevalent with new technology; and 3) those that are organisation specific, derived from the individual situation and set-up that the organisation is in when it begins the innovation initiative. These organisation specific forces are highly path dependant, based on past events and decisions made, as suggested in the work of Liebowitz and Margolis (1995) and David (1985), who recognised the effects history has on an organisation and its characteristics.

Measuring the success and failure of innovation is difficult (Armbruster et.al 2008), especially when comparing radical and incremental programmes. For a radical innovation to be a success, it is essential that all stages are achieved, whereas for incremental innovation every step is a success in itself, which may explain why Morton and Burns (2008) found that incremental innovations are more often successful. Culture also plays a huge part in innovation, as human factors are vital in achieving success (King, 1990; Kratzer et.al., 2005). It has been shown that the more open and supportive an organisation is to innovation and change in general, the greater it's potential for success; in line with the findings of Amabile et.al. (1996) and Zarrage and Bonache (2005). Results also show that those experiencing deeply entrenched routines and attitudes struggle to overcome them and encourage the level of involvement needed, corroborating the outcome of studies from Dougherty and Cohen, (1995) and Liefer et.al. (2000).

Finally, as Garcia and Calantone (2002) and Oke (2007) highlight, it is essential that an organisation understands the type of innovation it is embarking upon and what that potentially may involve, in order that it can plan and manage the initiative successfully. It is possible, however, that the steps involved and management style needed may not actually vary as much between the levels of innovation as would be expected, especially in large firms undertaking company-wide programmes, which forms a significant finding of this work.

\section{Limitations and further work}

Case study research has distinct advantages in the depth of knowledge that can be gained on a specific issue within an organisation; however, the findings are case 
specific. Although these findings have been discussed across the cases and certain commonalities found, it does not allow for automatic generalisation across the types of organisation or industries studied. This can only really be assessed with further comparison studies of organisations undertaking innovation at different levels and would benefit from the inclusion of those working at the mid levels of architectural and modular innovations.

\section{Acknowledgements}

The support of the Engineering and Physical Sciences Research Council under grant EP/C534239/1 and the Economic and Social Research Council under grant RES331270005 for this work is gratefully acknowledged.

\section{References}

Abernathy, W.J., and Clark, K.B., 1985. Innovation mapping the winds of creative destruction. Research Policy, 14, (1), 3-22.

Afuah, A.N., and Bahram, N., 1995. The hypercube of innovation. Research Policy, 24, 51-76.

Amabile, T. M., Conti, R., Coon, H., Lazenby J., and Herron M., 1996. Assessing the work environment for creativity. Academy of Management Journal, 39, (5), 1154-1184.

Anderson, N. R., and West, M. A., 1998. Measuring climate for work group innovation: development and validation of the team climate inventory. Journal of Organizational Behaviour, 19, (3), 235-258.

Andreua, R., and Ciborrab C., 1996. Organisational learning and core capabilities development: the role of IT. Journal of Strategic Information Systems, 5, 111127.

Arias-Aranda, D., Minguela-Rata, B., and Rodriguez-Duarte, A., 2001. Innovation and firm size: an empirical study for Spanish engineering consulting companies. European Journal of Innovation Management, 4, (3), 133-141.

Armbruster, H., Bikfalvi, A., Kinkel S., and Lay, G., 2008. Organizational innovation: The challenge of measuring non-technical innovation in large-scale surveys. Technovation, 28, 644-657

Arthur, W.B., 1989. Competing technologies, increasing returns, and lock-in by historical events. The Economic Journal, 99, (394), 116-131.

Babbar, S., and Rai, A., 1990. Computer integrated flexible manufacturing: an implantation framework. International Journal of Operations and Production Management, 10, (1), 42-50.

Battisti G., and Iona, A., 2009.The intra-firm diffusion of complementary innovations: Evidence from the adoption of management practices by British establishments. Research Policy, 38, 1326-1339

Baumol, W., 2002. The free-market innovation machine: analyzing the growth miracle of capitalism, Princeton, NJ: Princeton University Press. Cited in Bessant, J., and Venables, T. (2008), Creating wealth from knowledge: meeting the innovation challenge, Edward Elgar, Cheltenham, UK

Boas, T.C. (2007), "Conceptualizing Continuity and Change: The CompositeStandard Model of Path Dependence", Journal of Theoretical Politics, Vol.19, No.1, pp33-54 
Bryman, A., 1989. Research methods and organizational studies, contemporary social research: 20, Routledge, London,

Carayannis, E.G., and Turner, E., 2006. Innovation diffusion and technology acceptance: The case of PKI technology. Technovation, 26, 847-855

Cassell, C, and Symon, G., 2004. Essential guide to qualitative methods in organizational research, Sage Publications, London

Christensen, C., 2000. Something old, something new: 'the innovator's dilemma'. Economist, 354, (81), 15-19.

Coombs, R., and Hull R., 1998. 'Knowledge management practices' and path dependency. Innovation, Research Policy, 27, 237-253.

Damanpour, F., 1991. Organizational innovation: a meta-analysis of effects of determinants and moderators. The Academy of Management Journal, 34, (3), 555-590.

David, P.A., 1985. Clio and the Economics of QWERTY. The American Economic Review, 75, (2), 332-337. Papers and Proceedings of the Ninety- Seventh Annual Meeting of the American Economic Association.

David, P.A., 2001. Path dependence, its critics and the quest for 'historical economics', from the 'Keynote Address' to the European Association for Evolutionary Political Economy, at their Meetings held in Athens, 7-9 November 1997. Revised for publication in Evolution and path dependence in economic ideas: past and present, edited by P. Garrouste and S. Ioannides, Edward. Elgar Publishing, Cheltenham, England

Deeg, R., 2001. Institutional change and the uses and limits of path dependency: the case of German finance. MPIfG Discussion Paper, 1, (6)

Dezieck, J., 2003. Planning for change: the Force Field tool. OED Learning Topics. Massachusetts Institute of Technology, Available online at http://web.mit.edu/hr/oed/learn/ [accessed 03 March 2009]

Dhillon, B.S., 2006. Creativity for engineers. World Scientific Publishing Co. Ltd., London

Dobusch, L., 2007. Schumpeter vs. path dependency: innovation lessons from breaking through innovation barriers. The Fifth International Critical Management Studies Conference - Stream "Apollo Ante Portas! - Critical Perspectives on the Creative Age", Berlin

Dong, L., 2008. Exploring the impact of top management support of enterprise systems implementations outcomes: Two cases. Business Process Management Journal, 14, (2), 204-218

Dougherty, D., and Cohen, M., 1995. Product innovation in mature firms, in Bowman, E., and Kogut, B. (Eds.), 1995. Redesigning the firm, New York, Oxford University Press,

Eisenhardt, K.M., 1989. Building theories from case study research, The Academy of Management Review, 14, (4), 532-550.

Elliott, D., Swartz, E. and Herbane, B., 2001. Business continuity management. Routledge, London,

Freitas, I.M.B., 2008. Sources of differences in the pattern of adoption of organizational and managerial innovations from early to late 1990s, in the UK. Research Policy, 37, 131-148

Garcia, R., and Calantone, R., 2002. A critical look at technological innovation typology and innovativeness terminology: a literature review, The Journal of Product Innovation Management, 19, 110-132

Gillham, B., 2005. Case study research methods, Continuum, London 
Greener, I., 2005. State of the art: the potential of path dependence in political studies, Politics, 25, (1), 62-72

Greenwood, R. and Hinings, C. R., 1993. Understanding strategic change - the contribution of archetypes, Academy of Management Journal, 36, (5), 10521081.

Harty, C., 1998. Implementing innovation in construction: contexts, relative boundedness and actor-network theory. Construction Management and Economics, 26, 1029-1041

Henderson, R., and Clark, K., 1990. Architectural innovation: the reconfiguration of existing product technologies and the failure of established firms, Administrative Sciences Quarterly, 35, 9-30

Hill, C. W. L., and Jones G. R., 2004. Strategic management, 6th edition, Houghton Mifflin Publishing, Boston, MA

Jones, S. and Sims, D., 1993. Putting creativity on the map. Management Decision, $26,(3), 5-8$

King, N., 1990. Innovation at work: the research literature, in West, M.A. and Farr, J.L. (Eds.), 1990. Innovation and creativity at work: psychological and organizational strategies, Chichester, John Wiley \& Sons Ltd

Kratzer, J., Leenders, R. T. A. J. and Van Engelen, J. M. L., 2005. Informal contacts and performance in innovation teams. International Journal of Manpower, 26, (6), 513-528.

Lapointe, L., and Rivard, S., 2005. A multilevel model of resistance to information technology implementation. MIS Quarterly, 29, (3), 461-491

Larsen, G.D., 2005. Horses for courses: relating innovation diffusion concepts to the stages of the diffusion process. Construction Management and Economics, 23, 787-792

Leifer, R., McDermott, C.M., O'Connor, G.C., Peters, L.S., Rice, M.P., and Veyzer, R.W., 2000. Radical innovation how mature companies can outsmart upstarts, Boston, Massachusetts, Harvard Business School Press

Lewin, K., 1951. Field theory in social science: selected theoretical papers. Harper \& Row Publishers, New York

Liebowitz, S. J., and Margolis, S.E., 1990. The Fable of the Keys. Journal of Law and Economics, 33, 1-25.

Liebowitz, S. J. and Margolis, S.E., 1995. Path Dependence, Lock-In, and History. The Journal of Law, Economics and Organization, 11, (1), 205-226

Londeix, B., 1995. Deploying realistic estimation (field situation analysis). Information and Software Technology, 37, (12), 665-670

Lyytinen, K., and Rose, G.M., 2003. The Disruptive Nature of Information Technology Innovations: The Case of Internet Computing in Systems Development Organizations. MIS Quarterly, 27, (4), 557-596

Machuca, J.A.D., Sacristan Diaz, M., and Alvarez Gil, M.J., 2004. Adopting and implementing advanced manufacturing technology: new data on key factors from the aeronautical industry. International Journal of Production Research, 42, (16), 3183-3202.

Mazzoleni, R., 1997. Learning and path-dependence in the diffusion of innovations: comparative evidence on numerically controlled machine tools, Research Policy, 26, 405-428

Mersha. T., 1997. TQM implementation in LDCs: driving and restraining forces. International Journal of Operations and Production Management, 17, (2), 164183. 
Morton, S., and Burns, N., 2008. Understanding and overcoming resistance to innovation. In: Bessant, J., and Venables, T. (Eds.) Creating wealth from knowledge, MPG Books Ltd. Cornwall

Oke, A., 2007. Innovation types and innovation management practices in service companies. International Journal of Operations and Production Management, 27, (6), 564-587.

Oliver, S., and Harrison, J.J.H., 1996. A journey from bureaucracy to enterprise. Health Manpower Management, 1, 10-15

Panuwatwanich, K., Stewart, R.A., and Mohamed, S., 2009. Critical pathways to enhanced innovation diffusion and business performance in Australian design firms. Automation in Construction, 18, 790-797

Patel, P., and Pavitt, K., 1997. The technological competencies of the world's largest firms: complex and path-dependent, but not much variety. Research Policy, 26, 141- 156.

Peansupap, V. and Walker, D.H.T., 2006. Innovation diffusion at the implementation stage of a construction project: a case study of information communication technology. Construction Management and Economics, 24, 321-332

Perkmann, M., and Walsh, K., 2007. University-industry relationships and open innovation: Towards a research agenda. International Journal of Management Reviews, 9, (4), 259-280.

Ritchie, J., and Lewis, J., 2006. Qualitative research practice. Sage Publications, London

Rogers, E.M., 1995. Diffusion of innovations. The Free Press, New York

Rowley, J., 2002. Using case studies in research. Management Research News, 25, (1), 16-27

Salaheldin, S.I., 2003. TQM implementation: the implementation of TQM strategy in Egypt: a force field analysis. The TQM Magazine, 15, (4), 266-274.

Steele, J., and Murray, M., 2004. Creating, supporting and sustaining a culture of innovation. Engineering Construction and Architectural Management, 11, (5), 316-322.

Schwartz, H., 2004. Down the wrong path: path dependence, increasing returns, and historical institutionalism, Unpublished Manuscript, University of Virginia, available on-line at http://people.virginia.edu/ hms2f/Path.pdf [accessed 03 March 2009]

Schwering, R.E., 2003. Focusing leadership through Force Field analysis: new variations on a venerable planning tool. Leadership and Organization Development Journal, 24, (7), 361-370.

Sharma, R., and Yetton, P., 2003. The contingent effects of management support and task interdependence on successful information systems implementation. MIS Quarterly, 27, (4), 533-556

Sharma R., and Yetton P., 2007. The contingent effects of training, technical complexity, and task interdependence on successful information systems implementation. MIS Quarterly, 31 (2) 219-238

Swinton, L., Kurt Lewin's Force Field analysis: decision making made easy. Management for the Rest of Us, 2007. Available online at http://www.mftrou.com/Lewins-force-field-analysis.html [accessed 03 March 2009]

Teece, D.J., Pisano, G., and Shuen, A., 1997. Dynamic Capabilities and Strategic Management. Strategic Management Journal, 18, (7), 509-533

Tidd, J., 2006. Innovation models: discussion paper 1, Imperial College London 
Thakkar, J., Deshmukh, S.G., and Shastree, A., 2006. Total quality management (TQM) in self-financed technical institutions: a Quality Function Deployment (QFD) and Force Field analysis approach. Quality Assurance in Education, 14 (1), 54-74.

Thomas, J., 1985. Force Field analysis: a new way to evaluate your strategy. Long Range Planning, 18, (6), 54-59.

Topf, M.D., 2000. Managing change. Occupational Hazards, 62, (7), 43-44.

Utterback, J.M., 1996. Mastering the dynamics of innovation. Harvard Business School Press

Voss, C.A., 1986. Managing Advanced Manufacturing Technology. International Journal of Operations and Production Management, 6, (5), 4-7.

Wagner, H.T., Dainty A.R.J., Hague, R.J.M., Tuck, C.J. and Ong, M.H., (2008). The effects of new technology adoption on employee skills in the prosthetics profession. International Journal of Production Research, 46, (22), 6461-6478

Yin, R.K., 1981. The case study crisis: some answers. Administrative Science Quarterly, 26, 58-65. In Johnson, P., and Clark, M., 2006. Business and Management Research Methodologies, 4, Sage Publications, London,

Yin, R.K., 2003. Case study research: design and methods, Sage Publications, London

Yu, C.-S., and Tao, Y.-H., 2009. Understanding business-level innovation technology adoption. Technovation, 29, 92-109

Xue, C.G., Cao, H.W., and Gao, W., 2008. Research on diffusion behaviour of the Computer Integrated Manufacturing philosophy. Proceedings of the I Mech E, Part B: Journal of Engineering Manufacture, 222, 1025-1033

Zarraga, C., and Bonache J., 2005. The impact of team atmosphere on knowledge outcomes in self-managed teams. Organization Studies, 26, (5), 661-681 
Figure 1. Force Field Analysis diagram of the innovation process at Case 1

Figure 2. Force Field Analysis diagram of the innovation process at Case 2 
Figure 1 


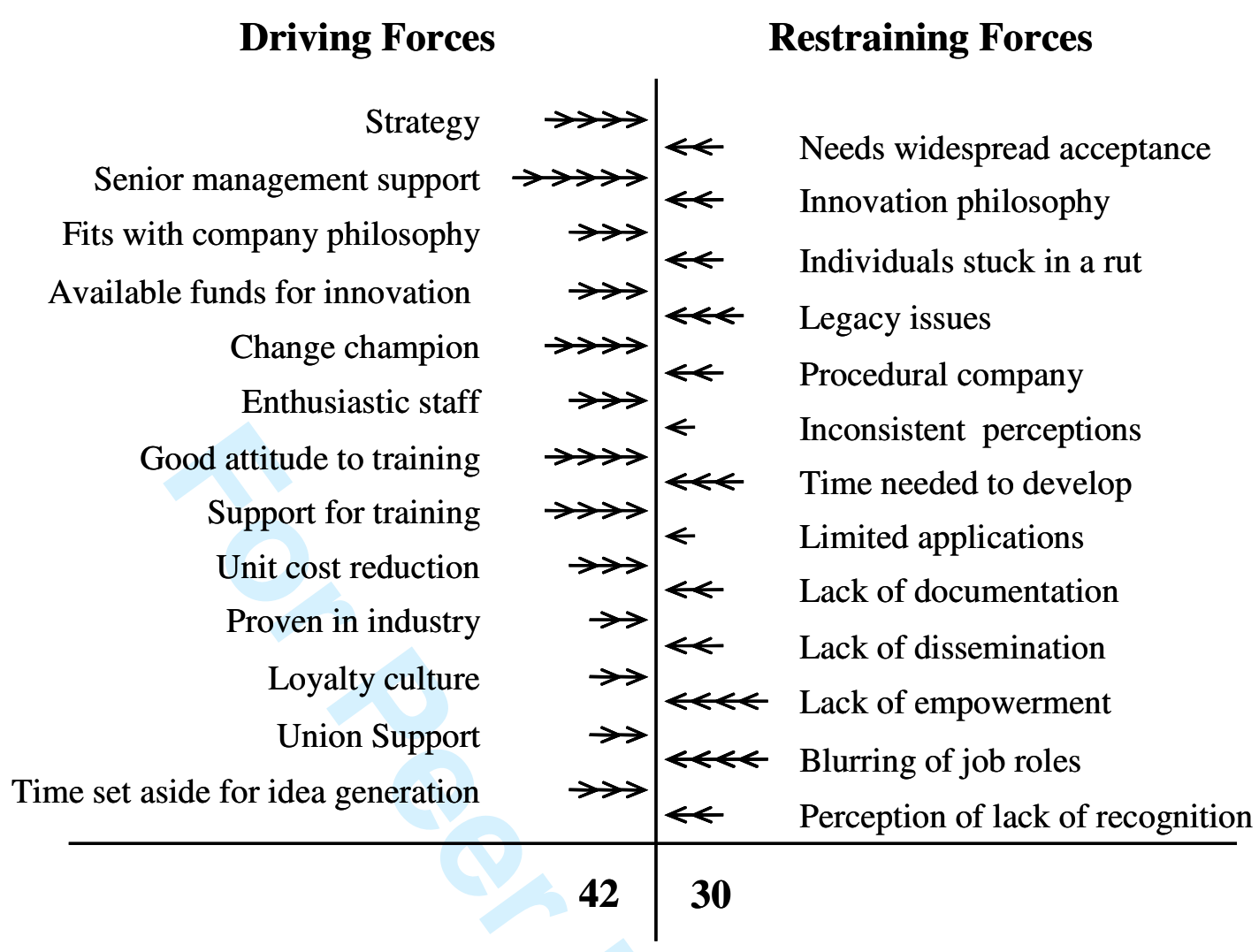

Figure 2 